\title{
Intrapartum fetal monitoring by cardiotocography and its correlation with labour outcome
}

\author{
Kanupriya Singh*, Mubassira Pathan, Mukul Shah
}

Department of Obstetrics and Gynecology, GCS Medical College, Hospital and Research Centre, Ahmedabad, Gujarat, India

Received: 24 August 2020

Accepted: 17 October 2020

*Correspondence:

Dr. Kanupriya Singh,

E-mail: drkanupriyasingh@gmail.com

Copyright: (c) the author(s), publisher and licensee Medip Academy. This is an open-access article distributed under the terms of the Creative Commons Attribution Non-Commercial License, which permits unrestricted non-commercial use, distribution, and reproduction in any medium, provided the original work is properly cited.

\section{ABSTRACT}

Background: The intrapartum fetal surveillance has gained significant importance. Avoidance of adverse fetal outcome is the objective of intrapartum fetal monitoring. This study helps in forming the aims to provide simple and clear approach to intrapartum fetal surveillance in high risk population.

Methods: In present study 80 laboring patients were analyzed retrospectively who were admitted in GCS Hospital from December 2017 to May 2018. Continuous fetal monitoring was done and results were correlated with maternal and fetal outcome.

Results: Cases with high risk (23) had more non-reassuring pattern of $8.7 \%$ as compared to low risk which had $5 \%$. With non-reassuring pattern, C-section was done in $38 \%$ whereas in reassuring pattern $85 \%$ had vaginal delivery. NICU admission in non-reassuring pattern were $7(63.6 \%)$ whereas in reassuring were only $2(2.89 \%)$. This makes false positivity as $36.4 \%$.

Conclusions: Predictive value of CTG of reassuring pattern is quite high. In spite of false positives, it is a very effective tool in labor room.

Keywords: Fetal Monitoring, Cardiotocograph, Reassuring/non-reassuring pattern

\section{INTRODUCTION}

The ultimate goal of every obstetrician is to deliver a neurologically healthy fetus to a healthy mother. Any result which fails to meet these goals leads to more introspection as far as intrapartum fetal monitoring methods are concerned. Traditionally fetal heart was monitored by intermittent auscultation or by hand doppler. With advent of cardiotocography, CTG machine has become a very important tool in labour room. For low risk patients intermittent auscultation is thought to be adequate but where a slightest chance of fetal hypoxia exists cardiotocography comes in forefront.

Cardiotocography provides an objective and reproducible evidence of fetal hypoxia that usually precedes neurological damage to fetal brain. This technique when introduced was readily incorporated in clinical practice without adequate clinical trials on large scale but later it also met with criticism for its false positivity.

Objective of our study was avoidance of adverse fetal outcome with intrapartum fetal monitoring. This study also helps in forming the aims to provide simple and clear approach to intrapartum fetal surveillance.

\section{METHODS}

Present study was conducted prospectively in department of Obstetrics and Gynecology, GCS Medical College and Hospital which is a tertiary referral Centre in Eastern Ahmedabad. 80 patients from December 2017 to May 2018 of labor were taken and CTG was applied to all these patients. 


\section{Inclusion criteria}

Inclusion criteria were, all term and near-term pregnancies, mild to moderate PIH/IUGR, mild to moderate anemia /oligohydramnios, previous LSCS (nonrecurrent), breech/Twins

\section{Exclusion criteria}

Exclusion criteria were preterm labour<33 weeks, antepartum hemorrhage, severe preeclampsia, fetal anomaly, medical disease of mother, severe maternal infection

In this study, the measure of pregnancy outcomes studied were mode of delivery, indications of caesarean section, percentage requiring caesarean section for fetal distress, oligohydramnios, meconium stained liquor. Early neonatal outcomes included were apgar score, birth weight, admission into neonatal intensive care unit (NICU), duration of stay in NICU and perinatal mortality. There were significant differences between the two groups regarding pregnancy outcomes and early neonatal outcomes.

In respect to endpoints, two main outcome variables were evaluated, relating to obstetric intervention (induction of labour, spontaneous vaginal delivery, operative vaginal delivery, emergency caesarean section), and perinatal outcome (subsequent perinatal death, low apgar scores, neonatal resuscitation, NICU admission) using Pearson chi square and Cramer's V test.

There are four main features that should be systematically examined to assist with the interpretation of the CTG: baseline rate, baseline variability, accelerations \& decelerations. The CTG tracings interpretation was based on RCOG/NICE guidelines-2001 (adopted by FIGO). On a sample of tracings, a re-evaluation of intra observer and interobserver agreement between two different obstetricians was conducted to confirm reliability of interpretations. A follow-up of perinatal and maternal outcomes was performed.

\section{RESULTS}

Primi and multi gravida women were observed for reassuring and non-reassuring patterns. incidence of nonreassuring pattern in primi was $13.9 \%$ as compared with multi gravida where incidence was $13.5 \%$. both had near equal incidence of non-reassuring patterns (Table 1).

Table 1: Parity and CTG Patterns.

\begin{tabular}{|llll|}
\hline & Number & Reassuring & $\begin{array}{l}\text { Non } \\
\text { reassuring }\end{array}$ \\
\hline Total & 80 & 69 & 11 \\
\hline Primigravida & 43 & 37 & 6 \\
\hline Multigravida & 37 & 29 & 5 \\
\hline
\end{tabular}

High incidence of non-reassuring pattern was noted in PIH. Out of total high-risk pregnancy incidence of nonreassuring pattern was seen in PIH group around $17 \%$ (Table 2).

Table 2: CTG patterns observed in high risk group.

\begin{tabular}{|llllll|}
\hline \multirow{2}{*}{$\begin{array}{l}\text { Sr. } \\
\text { no. }\end{array}$} & Cases & Total & \multicolumn{3}{c|}{$\begin{array}{l}\text { Non-reassuring } \\
\text { pattern }\end{array}$} \\
\hline $\mathbf{1}$ & PIH & 10 & 4 & 3 & 1 \\
\hline $\mathbf{2}$ & PROM & 2 & 1 & 0 & 0 \\
\hline $\mathbf{3}$ & $\begin{array}{l}\text { Oligohydra } \\
\text { mnios }\end{array}$ & 1 & 1 & 1 & 1 \\
\hline $\mathbf{4}$ & IUGR & 2 & 1 & 0 & 0 \\
\hline $\mathbf{5}$ & Diabetes & 0 & 1 & 0 & 1 \\
\hline & Total & 15 & 8 & 4 & 3 \\
\hline
\end{tabular}

Comparison of CTGs of patients In Spontaneous labor and induced labour. Non reassuring pattern was $13 \%$ as compared to $18 \%$ in Induced labor. So, induction of labour pts had higher incidence of CTG abnormality (Table 3).

Table 3: Patterns as per spontaneity of labor versus induction.

\begin{tabular}{|llll|}
\hline Sr. no & & Reassuring & Non-reassuring \\
\hline $\mathbf{1}$ & Spontaneous & 60 & 9 \\
\hline $\mathbf{2}$ & Induced & 9 & 2 \\
\hline & Total & 69 & 11 \\
\hline
\end{tabular}

Non-reassuring pattern was $8.75 \%$ in high risk pregnancies as compared to $5 \%$ in low risk pregnancies (Table 4).

Table 4: CTG patterns observed as per risk factors.

\begin{tabular}{|llllll|}
\hline Sr. & Cases & \multicolumn{2}{c}{ Total } & \multicolumn{3}{c|}{$\begin{array}{l}\text { Non-reassuring } \\
\text { pattern }\end{array}$} \\
no. & No. & $\%$ & No. & $\%$ \\
\hline 1. & $\begin{array}{l}\text { No risk } \\
\text { Factor }\end{array}$ & 57 & 71.25 & 4 & 5 \\
\hline 2. & $\begin{array}{l}\text { High risk } \\
\text { Factor }\end{array}$ & 23 & 28.75 & 7 & 8.75 \\
\hline & Total & 80 & & 11 & \\
\hline
\end{tabular}

Table 5: Correlation with meconium vs clear liquor.

\begin{tabular}{|llccc|}
\hline Fetal rate & \multicolumn{2}{c}{ Meconium stained } & \multicolumn{2}{c|}{ Clear liquor } \\
patterns & No. & $\%$ & No. & $\%$ \\
\hline Reassuring & 7 & 58 & 62 & 91 \\
\hline $\begin{array}{l}\text { Non- } \\
\text { reassuring }\end{array}$ & 5 & 42 & 6 & 9 \\
\hline Total & 12 & & 68 & \\
\hline
\end{tabular}


Incidence of meconium staining of liquor was high in non-reassuring pattern which was around $42 \%$ as compared to reassuring pattern was around $7 \%$. In clear liquor, reassuring pattern was high (Table 5).

Mode of delivery in reassuring pattern was vaginal route mainly $(85 \%)$ whereas in non-reassuring pattern vaginal delivery was about $62 \%$ as compared to caesarean section which was $15 \%$ in reassuring pattern and 38\% in nonreassuring pattern (Table 6).

Table 6: CTG correlation with mode of delivery.

\begin{tabular}{|lllllll|}
\hline Sr. & FHR Patterns & No. & \multicolumn{2}{c|}{$\begin{array}{l}\text { Vaginal } \\
\text { delivery }\end{array}$} & \multicolumn{2}{c|}{ Caesarean } \\
\cline { 3 - 7 } no. & & & No. & \% & No. & \% \\
\hline 1. & Reassuring & 69 & 58 & 85 & 11 & 15 \\
\hline 2. & Non-reassuring & 11 & 8 & 62 & 3 & 38 \\
\hline & Total & 80 & 65 & & 15 & \\
\hline
\end{tabular}

NICU admission was quite high in non-reassuring pattern $(63.6 \%)$ as compared to reassuring pattern which was quite low about $2.89 \%$ (Table 7).

Table 7: NICU admission.

\begin{tabular}{|c|c|c|c|c|c|c|c|}
\hline \multirow{2}{*}{$\begin{array}{l}\text { Sr. } \\
\text { no. }\end{array}$} & \multirow{2}{*}{$\begin{array}{l}\text { FHR } \\
\text { patterns }\end{array}$} & \multicolumn{2}{|c|}{$\begin{array}{l}\text { No NICU } \\
\text { admission }\end{array}$} & \multicolumn{2}{|c|}{$\begin{array}{l}\text { NICU } \\
\text { admission }\end{array}$} & \multicolumn{2}{|c|}{ Total } \\
\hline & & & $\%$ & $\begin{array}{l}\mathbf{N} \\
\mathbf{o .}\end{array}$ & $\%$ & $\begin{array}{l}\mathbf{N} \\
\mathbf{0}\end{array}$ & $\%$ \\
\hline 1. & Reassuring & 67 & 97.1 & 2 & 2.89 & 69 & 86.25 \\
\hline 2. & $\begin{array}{l}\text { Non- } \\
\text { reassuring }\end{array}$ & 4 & 36.3 & 7 & 63.6 & 11 & 13.75 \\
\hline & Total & 71 & & 9 & & 80 & \\
\hline
\end{tabular}

Mean APGAR score was higher in reassuring pattern as compared to non-reassuring pattern, in non-reassuring pattern mean was as low as 5 (Table 8).

Table 8: Apgar score.

\begin{tabular}{|llll|}
\hline $\begin{array}{l}\text { Sr. } \\
\text { no. }\end{array}$ & FHR Pattern & $\begin{array}{l}\text { Total } \\
\text { cases }\end{array}$ & $\begin{array}{l}\text { Mean APGAR } \\
\text { score at } \mathbf{5} \text { min. }\end{array}$ \\
\hline I. & Reassuring & 69 & 8 \\
\hline II. & Non-reassuring & 11 & 5 \\
\hline
\end{tabular}

\section{DISCUSSION}

Depending upon parity in primigravida incidence of nonreassuring pattern was $13.9 \%$ as compared to multigravidas which was $13.5 \%$. In high risk group in primigravidas more non-reassuring pattern were seen in hypertensive patients i.e $30 \%$. In oligohydramnios the incidence of non-reassuring pattern was equally high in multi and primigravida. In PROM and IUGR, incidence was low. Overall incidence of non-reassuring heart rate was $8.75 \%$ in high risk pregnancies as compared to $5 \%$ in low risk pregnancies. In a comparative studies of Sandhu et al abnormal CTGs' were observed in $10 \%$ of high-risk pregnancies. ${ }^{13}$ In Hafizur Rahman et al study 2012 there was $8.7 \%$ incidence of omnious CTG in high risk group. $^{12}$

In meconium stained liquor non-reassuring fetal heart rate pattern was present in $42 \%$, whereas in clear liquor $91 \%$ had reassuring pattern. This is statistically significant $\mathrm{p}<0.001$. Rehman et al showed $72 \%$ patient of MSL having non-reassuring pattern. ${ }^{12}$

Cesarean section rate was $38 \%$, in non-reassuring pattern as compared to $15 \%$ in reassuring pattern. In a study by Daneilian et al $51.8 \%$ with abnormal CTG results had caesarean section. ${ }^{9}$

NICU admission rate was $63.6 \%$ in non-reassuring pattern as compared to reassuring $(2.89 \%) .{ }^{6,7}$ Similar findings were shown by Sharbaf and Rahimi et al in Sandhu et-al study group neonatal admissions were $33 \%$ with abnormal CTGs. ${ }^{14}$

Mean APGAR score was 8 in reassuring pattern as compared to 5 in non-reassuring pattern. ${ }^{8,9}$ In a comparable study by EH Delinger et al in apgar scores were depressed in $75 \%$ with abnormal CTGs. ${ }^{6}$

\section{CONCLUSION}

CTG is a simple non-invasive test and can help obstetrician in timely intervention. It is an efficient device in busy labour units with limited resources. Despite limitations, continuous CTG monitoring should be considered in all situations where there is a high risk of fetal hypoxia/acidosis. It should also be considered in predisposing maternal factors (Preeclampsia, Diabetes). In cases of induced or augmented labour where there is probability of hyper-stimulation, electronic fetal monitoring should be considered. Also, in fetal growth retardation, meconium stained liquor or where any abnormality detected during intermittent fetal auscultation CTG is recommended. It provides a recordable proof of fetal well-being in case of adverse outcome which can be helpful in growing era of litigation.

\section{Funding: No funding sources \\ Conflict of interest: None declared \\ Ethical approval: The study was approved by the Institutional Ethics Committee}

\section{REFERENCES}

1. Alfirevic Z, Devane D, Gyte GM. Continuous cardiotocography (CTG) as a form of electronic fetal monitoring (EFM) for fetal assessment during labour. Cochrane Database Syst Rev. 2013;5:CD006066. 
2. Vintzileos AM, Nochimson DJ, Guzman ER, Knuppel RA, Lake M, Schifrin BS. Intermittent electronic fetal heart rate monitoring versus intermittent auscultation: a Meta-Analysis. Obstet Gynecol. 1995;85(1):149-55.

3. Royal College of Obstetricians and Gynaecologists. The use of electronic fetal monitoring. Evidencebased clinical guideline, number 8 . London: RCOG Press; 2001.

4. Herbst A, Ingemarsson I. Intermittent versus continuous electronic fetal monitoring in labour: a randomized study. $\mathrm{Br} \mathrm{J}$ Obstet Gynaecol. 1994;101(8):663-8.

5. Nunes I, Ayres-de-Campos D, Figueiredo C, Bernardes J. An overview of central fetal monitoring systems in labour. J Perinat Med. 2013;41(1):93-9.

6. Delinger EH, Boehm FH, Crane M M. Electronic Fetal Heart Rate Monitoring: Early neonatal outcome associated with normal rate, fetal stress \& fetal distress. Am J Obstet Gynecol. 2000:182:214-98

7. Sameshima H, Ikenoue T, Ikeda T, Kamitomo M, Ibara S. Unselected low-risk pregnancies and the effect of continuous intrapartum fetal heart rate monitoring on umbilical blood gases and cerebral palsy. Americ J Obstet Gynecol. 2004;190(1):11823.

8. Harrington DJ, Redman CW, Moulden M, Greenwood CE. The long-term outcome in surviving infants with Apgar zero at 10 minutes: a systematic review of the literature and hospital-based cohort. Am J Obstet Gynecol. 2007;196:463.
9. Danielian P, Steer PJ. Fetal distress in labour: high risk pregnancy management option. 3rd ed. New Delhi. Elsevi. 2006;1450-72.

10. Balchin I, Whittaker JC, Lamont RF, Steer PJ. Maternal and fetal characteristics associated with meconium-stained amniotic fluid. Obstet Gynecol. 2011;117(4):828-35.

11. Hiersch L, Krispin E, Aviram A, Wiznitzer A, Yogev Y, Ashwal E. Effect of meconium-stained amniotic fluid on perinatal complications in low-risk pregnancies at term. Americ J Perinatol. 2016;33(04):378-84.

12. Rahman H, Renjhen P, Dutta S, Kar S. Admission cardiotocography: Its role in predicting foetal outcome in high-risk obstetric patients. Australas Medic J. 2012;5(10):522-7.

13. Sandhu GS, Raju R, Bhattacharyya TK. Admission cardiotocography screening of high-risk obstetric patients. Medic J Arm Forc Ind. 2008;64(1):43-5.

14. Sharbaf FR, Amjadi N, Alavi A, Akbari S, Forghani F. Normal and indeterminate pattern of fetal cardiotocography in admission test and pregnancy outcome. J Obstet Gynaecol Resear. 2014;40(3):6949 .

Cite this article as: Singh $\mathrm{K}$, Pathan M, Shah M. Intrapartum fetal monitoring by cardiotocography and its correlation with labour outcome. Int J Reprod Contracept Obstet Gynecol 2020;9:4937-40. 